\title{
The Rehabilitative Guidance via WeChat Platform on Postoperative Dirigation of Children with Developmental Dislocation of the Hip
}

\author{
Jing $\mathrm{Li}^{1, \mathrm{a}}$, Yan $\mathrm{Li}^{2, \mathrm{~b}}$, Dong-Ying $\mathrm{Li}^{3, \mathrm{c}}$, Chun-Wen $\mathrm{Li}^{4, \mathrm{~d}}$ and Chun-Ying $\mathrm{Li}^{4, \mathrm{e}^{*}}$ \\ ${ }^{1}$ Nursing College of Beihua University, Jilin Province, China \\ ${ }^{2}$ Foreign Language College of Beihua University, Jilin Province, China \\ ${ }^{3}$ Sixth People's Hospital of Jilin city, Jilin Province, China \\ ${ }^{4}$ Beihua University, Jilin Province, China \\ a9291490@qq.com, b31433593 @qq.com, ${ }^{\text {c}} 46611108$ @qq.com, \\ d1138382876@qq.com, ${ }^{\mathrm{e}}$ Icythunder@163.com *Correspondence authors
}

\begin{abstract}
Keywords: WeChat platform; Developmental dislocation of the hip (DDH); Rehabilitative guidance; Nursing intervention; Postoperative
\end{abstract}

\begin{abstract}
Object: To investigate The rehabilitative guidance via wechat platform on postoperative dirigation of children with DDH. Methods: After plaster immobilization, 32 children with a comprehensive nursing intervention are compared to 37 with traditional nursing. X-ray is employed to examine and record the therapeutic effect based on the evaluation standard of DDH. The clinical outcome, X-ray results, overall acceptance rate, compliance and the subluxation rate are compared between the two groups. SPSS 17.0 statistical software is applied for statistical analysis. Results: 1 . The compliance in the intervention group in the 6th week is significantly better than the traditional group ( $\mathrm{p}<0.05) .2$. The clinical outcome, $\mathrm{X}$-ray results, overall acceptance rate, and compliance in the intervention group in the 3th and 4th month are significantly better than the traditional group $(\mathrm{p}<0.05)$. 3. The clinical outcome, X-ray results, overall acceptance rate, compliance and subluxation in the intervention group in the 5th and 6th month are significantly better than the traditional group $(\mathrm{p}<0.05)$. Conclusion: A comprehensive intervention in hospital and postoperative rehabilitative guidance via WeChat can not only improve the clinical evaluation, X-ray evaluation, but also the compliance of children with family members, thus improve children's overall crop.
\end{abstract}

\section{Introduction}

Developmental dislocation of the hip joint is a common ailment. For moderate and severe children aged from 1.5 to 8 , the sooner the operation is made, the better the result will be. On clinical stage, hip-shelf procedure femoral rotational osteotomy orthopedy will be performed, postoperative plaster immobilization will last for 6 weeks. However, the stitches will be taken out 14 days after the operation, while the plaster will be remained when leaving the hospital. Literally, the clinical stage is terminated. Large space is left for rehabilitative guidance on how to provide assistance to the child, which has great influence on dirigation of the hip joint as well as his gait.

\section{Research Subject and Methodology}

Research Subject. Children with developmental dislocation of the hip joint who are in hospital between Jan. 2013 to May 2014 and meet the requirements of research are chosen as the subjects. Research requirements are: 1. Children who are diagnosed as developmental dislocation of the hip joint; 2. Children who will be performed hip-shelf procedure femoral rotational osteotomy orthopedy, and postoperative plaster immobilization will last for 6 weeks, the stitches will be taken out 14 days after the operation, while the plaster will be remained when leaving the hospital; 3 . Children who are unilaterally operated and initially operated, aged from 1.5 to 8 ; 4 . Children whose parents are aware of the research and voluntarily participate in the research. 
Altogether 69 children are chosen as the research subjects. Based on the objective elements and their personal will, the subjects are divided into 2 groups: 32 are in experimental group, among which 9 males and 23 females, 18 unilateral dislocation and 14 bilateral dislocation, aged (2.2 \pm 0.8$)$; 37 are in control group, among which 11 males and 26 females, 20 unilateral dislocation and 17 bilateral dislocation, aged (2.0 \pm 0.9$)$. The control group will receive routine guidance after leaving hospital, while the experimental group will receive rehabilitative guidance on dirigation at regular time with the help of Internet platform.

\section{Methodology}

1) Rehabilitative guidance: With the help of massive reference and clinical practice, dirigation program will be made, relevant audio-visual materials will be posed on the Internet platform.

2) Within 6 weeks after operation, parents acquire audio-visual materials via Wechat platform to assist child to do the followingexercise:1.contractile activity of quadriceps muscle of thigh is needed, 3 times per day, 5-10 mins per time. 2. Within plaster immobilization period, "stoop and fetch" game is encouraged. Gradually enlarge the angle of flexion of the hip joint, move toy forward step by step along with the plaster beam, practice the flexion of the hip joint. 3. Plaster will be removed 6 weeks after the operation. Do not force child to be in lap position within the first 3 days without plaster. Follow in proper sequence. 4. Do not hold child with single hand. Parent is expected to hold hips with both hands to make the child in trestle posture. The angle between legs is no less than 50 degree. Under this circumstance, the caput femoris is entirely enfolded in joint capsule and in remedy position, not likely to dislocate again.

3) 7 weeks to 3 months after operation, parents acquire audio-visual materials via Wechat platform to assist child to do the followingexercise:1. Strengthen dirigation of the hip joint and the knee joint by wathcing videos on the Internet. Foment on the hip joint 20-30 mins before dirigation. After foment, undertake passive practice on the joint, pause for 5 secs when pain or obvious resistance is felt, then slightly enlarge the angle, hold for 5-10 secs, 15-20 times per unit, 3-5 units per day. 2. When child is able to walk, protective assistance is needed within the first 3 days. 3 . Strengthen the dirigation on flexion of the hip joint and the knee joint. Hold both hands of the child, squat down. When resistance is felt, slightly continue and hold the posture for 5 secs, 20 times per unit, 3 units per day. 4. When child is able to walk by himself, there is no need to remedy his walking posture. Walking posture will be gradually improved to normal level along with his body development. In this period, lengthen squat-down playing time to reinforce the stability of the hip joint. 5. Strengthen squat-down action. When child is able to squat down by himself, protect child from tumble. When the angle of flexion of the hip joint is nearly 120 degree, i.e. his knee joint is completely close to his chest, encourage child to both heelstrike. 6. Abduction and intorsion practice is expected.

4) 3 months to 6 months after operation, parents acquire audio-visual materials via Wechat platform to assist child to do the followingexercise:1. Encourage child to play in squat-down posture, both heelstrike, and both knees completely close to chest. 2 . Lessen dangerous actions like run and jump to avoid fracture. 3. Check dirigation program once a week.

5) Follow-up research are taken on each and every subject within 6-8 months. Countercheck are taken respectively on 6 weeks, 3 months, and 6 months after operation. The experimental group is in charge of professional researchers who communicate with parents once a week, verbally or audio-visually, to garuntee the rehabilitative guidance of dirigation. The control group has neither dirigation program nor vedio guidance.

\section{Research Tool}

a) Healing efficacy rating scale of $\mathrm{DDH}$ : Healing efficacy rating scale of congenital dislocation of the hip joint is applied. Evaluation criteria of acceptance rate is as follow: A---26-30, B---21-25, C---16-20, D--- $<15$.

b) Compliance formula: Compliance=days of parents applying "nursing intervention measure" / days in total $\times 100 \%$ 


\section{Statistical Analysis}

All the experimental data will be analyzed via Statistical Package for Socail Science (SPSS 17.0). The comparison between two groups on age, clinical evaluation, $\mathrm{X}$-ray evaluation is conducted by $\mathrm{t}$ test; the comparison between two groups on gender, dislocation side, postoperative overall acceptance rate, postoperative subluxation rate and compliance is conducted by chi square test. $\mathrm{P}<0.05$ shows statistical significance.

\section{Result}

Preoperative comparison of general information between two groups:The age, dislocation data, clinical evaluation, X-ray evaluation of experimental group and control group show no statistical significance $(\mathrm{P}>0.05)$.

Table

\begin{tabular}{|c|c|c|c|c|}
\hline Item & $\begin{array}{l}\text { Control } \\
\text { group } \\
(\mathrm{n}=37)\end{array}$ & $\begin{array}{l}\text { Experimental } \\
\text { group } \\
(\mathrm{n}=32)\end{array}$ & $\begin{array}{l}\text { 合计 total } \\
\mathrm{n}=69\end{array}$ & $\mathrm{P}$ \\
\hline Gender (Male, \%) & $11(29.7)$ & $9(28.1)$ & $20(29.0)$ & 0.45 \\
\hline Age & $2.0 \pm 0.9$ & $2.2 \pm 0.8$ & $2.1 \pm 0.7$ & 0.78 \\
\hline Dislocation (Left, \%) & $17(45.9)$ & $14(43.8)$ & $31(44.9)$ & 0.53 \\
\hline Clinical evaluation & $7.9 \pm 1.9$ & $7.7 \pm 1.7$ & $7.8 \pm 2.0$ & 0.74 \\
\hline $\mathrm{X}$-ray evaluation & $8.4 \pm 1.2$ & $8.8 \pm 1.4$ & $8.7 \pm 1.6$ & 0.59 \\
\hline
\end{tabular}

6 weeks after operation, comparison on rehabilitative situation after plaster removal:The compliance of the experimental group is seemingly superior than that of the control group, which shows statistical significance $(\mathrm{P}<0.05)$; however, the overall healing efficacy of the two groups shows no statistical significance $(\mathrm{P}>0.05)$.

Table 2 Postoperative comparison on healing efficacy and compliance after

\begin{tabular}{lllll}
\hline \multicolumn{1}{c}{ Item } & $\begin{array}{l}\text { Control } \\
\text { group } \\
(\mathrm{n}=37)\end{array}$ & $\begin{array}{l}\text { Experimenta } \\
1 \text { group } \\
(\mathrm{n}=32)\end{array}$ & $\begin{array}{l}\text { 合计 } \\
\text { total } \\
\mathrm{n}=69\end{array}$ & $\mathrm{P}$ \\
& & & & \\
& $6.3 \pm 1.1$ & $6.1 \pm 1.3$ & $6.2 \pm 1.4$ & 0.37 \\
\hline $\begin{array}{l}\text { Clinical } \\
\text { evaluation }\end{array}$ & & & & \\
X-ray evaluation & $10.9 \pm$ & $11.2 \pm 1.3$ & $11.1 \pm$ & 0.46 \\
& 1.2 & & 1.5 & \\
0verall acceptance & $5(13.5)$ & $4(12.5)$ & $9(13.0)$ & 0.51 \\
rate(n, \%) & & & & \\
Compliance (\%) & $67.5 \pm$ & $82.5 \pm 10.2$ & $71.2 \pm$ & 0.01 \\
& 12.3 & & 15.1 & \\
Subluxation(n, \%) & $0(0)$ & $0(0)$ & $0(0)$ & 1.00 \\
& & & & \\
\hline
\end{tabular}

3 months after operation, comparison on rehabilitative situation: The clinical evaluation, X-ray evaluation, overall acceptance rate and compliance of the experimental group is obviously superior than that of the control group, which shows statistical significance $(\mathrm{P}<0.05)$; however, the subluxation of the two groups shows no statistical significance $(\mathrm{P}>0.05)$. 
Table 33 months after operation, comparison on rehabilitative situation

\begin{tabular}{|c|c|c|c|c|}
\hline Item & $\begin{array}{l}\text { Control } \\
\text { group } \\
(n=37)\end{array}$ & $\begin{array}{l}\text { Experimental } \\
\text { group } \\
(\mathrm{n}=32)\end{array}$ & $\begin{array}{l}\text { 合计 } \\
\text { total } \\
n=69\end{array}$ & $P$ \\
\hline Clinical evaluation & $6.7 \pm 1.7$ & $8.9 \pm 1.3$ & $\begin{array}{l}7.4 \pm \\
1.8\end{array}$ & 0.02 \\
\hline $\mathrm{X}$-ray evaluation & $9.5 \pm 1.1$ & $12.1 \pm 1.3$ & $\begin{array}{l}10.1 \pm \\
1.6\end{array}$ & 0.03 \\
\hline $\begin{array}{l}\text { Overall acceptance } \\
\text { rate }(n, \%)\end{array}$ & $7(18.9)$ & $15(46.9)$ & $\begin{array}{l}22(31 . \\
9)\end{array}$ & 0.00 \\
\hline Compliance (\%) & $65.7 \pm 14.7$ & $84.1 \pm 9.3$ & $\begin{array}{l}70.4 \pm \\
15.3\end{array}$ & 0.00 \\
\hline Subluxation $(\mathrm{n}, \%)$ & $1(2.7)$ & $0(0)$ & $1(1.4)$ & 0.12 \\
\hline
\end{tabular}

6 months after operation, comparison on rehabilitative situation: The clinical evaluation, X-ray evaluation, overall acceptance rate and compliance of the experimental group is obviously superior than that of the control group, which shows statistical significance $(\mathrm{P}<0.05)$; the subluxation of the two groups shows statistical significance $(\mathrm{P}<0.05)$.

Table 4 Postoperative comparison on healing efficacy and compliance after 6 months

\begin{tabular}{lllll}
\hline \multicolumn{1}{c}{ Item } & $\begin{array}{l}\text { Control } \\
\text { group } \\
(\mathrm{n}=37)\end{array}$ & $\begin{array}{l}\text { Experimental } \\
\text { group } \\
(\mathrm{n}=32)\end{array}$ & $\begin{array}{l}\text { 合计 } \\
\text { total } \\
\mathrm{n}=69\end{array}$ & $\mathrm{P}$ \\
& $9.9 \pm 1.8$ & $13.8 \pm 1.4$ & $\begin{array}{l}11.3 \pm \\
1.9\end{array}$ & 0.00 \\
\hline Clinical evaluation & $9.9 \pm 1.9$ & $12.2 \pm 1.4$ & $11.8 \pm$ & 0.00 \\
& & & 2.2 & \\
X-ray evaluation & $8.9(90.6)$ & $52(75$. & 0.00 \\
Overall acceptance & $23(62.2)$ & $29(90)$ & $4)$ & \\
rate(n, \%) & & & $71.1 \pm$ & 0.00 \\
Compliance(\%) & $63.3 \pm 19.2$ & $85.6 \pm 7.1$ & 20.1 & \\
& & & $4(5.8)$ & 0.01 \\
\hline Subluxation(n, \%) & $4(10.8)$ & $0(0)$ & & \\
\hline
\end{tabular}

\section{Discussion}

An analysis on rehabilitative guidance effect after leaving hospital

Since a lack of nursing follow-up, it is hardly to find reports on parents' nursing knowledge home and abroad. After leaving hospital, the clinical treatment is terminated though the overall treatment is not completed. Rehabilitative practice is a crucial part in orthopaedics and has fateful influence on children's rehabilitation. This paper aims at providing prevention and treatment method for a series of problems like anchylosis after DDH operation by offering scientific rehabilitative guidance with the help of Internet, telephone, etc.. By doing this, both the clinical evaluation and X-ray evaluation can be improved. Furthermore, the overall acceptance rate is increased. It can be found that this method works positively on improving the joint function after operation.

Advantages of WeChat platform in postoperative rehabilitative guidance

WeChat platform is a newly developed means of communication, which is enjoyed by the vast majority of young parents. Developmental dislocation of the hip joint is a common ailment. China is of high prevalence of this disease and has a long way to go in early-diagnose and early-therapy of it compared to those developed countries. Nevertheless, along with the development of Internet, 
Wechat platform offers great help in publicizing DDH with pictures. Screening for DDH is not obligatory in China; however, with the help of Internet, high risk group still can be noticed since young parents' attention has been drawn. After operation, also with the help of Internet, the rehabilitative situation can be monitored and followed up, verbally or audio-visually, which avoids the possibility of misevaluation on rehabilitation because of the ambiguity that may be produced in an improper expression. Meanwhie, the compliance of preventing and treating anchylosis is improved.

In the following research, the rehabilitative guidance program will be perfected step by step, including audio-visual materials, which will provide parents direct and scientific foundation to practice after operation and meanwhile reduce the possibility of complicating diseases because of inefficient rehabilitative practice.

\section{Acknowledgment}

The research work was supported by education department of Jilin Province (No.2015168, No.201672), science and technology department of Jilin City (No.201536062).

\section{References}

[1] Wang Nan, Qin Qian, Ye Lei. Postoperative nursing care of infants with developmental dislocation of the hip treated with Ferguson [J]. Modern clinical nursing. 2013,12(7):33-35.

[2] Wang Suzhen, Weipomann, Zhao Ling. Nursing care of elderly children with hip dislocation after early traction under functional training $[\mathrm{J}]$. Chinese Journal of practical nursing 2016,22(2):20-21.

[3] Sun Hongxia, Ding Juan. Nursing experience of developmental dislocation of the joint [M]. 2012 , pp. 356.

[4] Li Li, Dong Xiuli, Qin Xiang. Observation and nursing care of developmental dislocation of the hip in infants treated with plaster fixation [J]. Journal of nursing education. 2009, 24(20):1857-1858.

[5] Yang Chunmei, Huang Yangyun, Yang Jianhua. Application of hip and ankle orthosis in rehabilitation nursing of developmental dislocation of hip in children [J]. Chinese Journal of clinical nursing. 2013,5(5):415-416.

[6] Staheli LT, Pan Shaochuan translation. Practical pediatric orthopedics[M]. Beijing : People's Medical Publishing House.2007, pp.166.

[7] Yang Xue, Li Yanhua. Perioperative nursing care of children with developmental dislocation of hip joint treated with osteotomy [J]. Nursing practice and research. 2012,9(22):54-56.

[8] Zheng Ruizhen, Li Bingzuan, Zhuang Qiongxia. Long term follow-up of pediatric patients with developmental dislocation of the hip [J]. Nursing practice and research 2013,10(13):133134.

[9] U. GuneyOzerErgun, Murat Uzel, Mustafa Celik ,et al. The knowledge, attitude and practice of the primary and secondary care nurse-midwife practitioners on developmental dysplasia of hip[J]. Nurse Education Today. 2007,27(2):635-642.

[10] Sonya Clarke PGCert, BSc, RN, et al. An audit of spica cast guidelines for parents and professionals caring for children with developmental dysplasia of the hip[J].Journal of Orthopaedic Nursing, 2006,10(1): 128-137. 